


\title{
Prevalence of ixodid ticks infesting Raya cattle breeds in Semi-arid areas of Raya Azebo district, northern Ethiopia
}

\author{
Meseret Hadgu ${ }^{1,2 *}$, Habtamu Taddele ${ }^{2,3}$, Atkilt Girma ${ }^{2}$, Haftu Abrha ${ }^{2}$, Haftom Hagos ${ }^{2}$ \\ ${ }^{1}$ Tigray Agricultural Marketing Promotion Agency, Mekelle, Ethiopia \\ ${ }^{2}$ Institute of Climate and Society, Mekelle University, Ethiopia \\ ${ }^{3}$ College of Veterinary Medicine, Mekelle University, Ethiopia \\ *Corresponding author Email: meserethadgu2006@gmail.com
}

\begin{abstract}
A cross-sectional study was conducted from January to December, 2016 in Semi-arid areas of Raya Azebo District with the objectives to estimate the prevalence of ixodid ticks and assessing the difference in infestation among the different host risk factors such as age, sex and body condition scores. A total of 2697 adult ixodid ticks were collected from 488 Raya cattle breed selected randomly. Tick species were identified morphologically and the prevalence of the infested animals was estimated in relation to sex, age and body condition score. The study revealed that cattle in the study area were infested with atleast one or more ticks with an overall prevalence of 90\% (405/448). Six tick species that belongs to the genera of Rhipicephalus (54\%), subgenus Boophilus (5\%), Amblyomma (3\%) and Hyalomma (2.7\%) were also identified. The overall prevalence of ticks on cattle with the age from 6 months to 2 years, 3-5 years and greater than 5 years was $90 \%, 90 \%$, and $92 \%$ respectively. A prevalence of $91 \%$ in female and $90 \%$ in male cattle was also observed. Similarly, the prevalence of ticks was $100 \%, 90.7 \%$ and $70 \%$ in poor, medium and good body conditioned animals, respectively. The high prevalence and presence of many species of ticks may damage the hide and skins of the cattle and thereby contribute to reduced income from cattle. Hence, appropriate control measures using acaricides, improved cattle management practices and community awareness creation are recommended.
\end{abstract}

Keywords: Body condition; Cattle; Prevalence; Semi-arid; Tick 


\section{Introduction}

Livestock in Ethiopia is one of the largest components of the agricultural sector (Gashaw et al., 2014) which contributes to the national socio-economy. The calculated combined total output gross value of livestock product is Birr 74.338 billion which is $47.7 \%$ of agricultural GDP of the country and $16.5 \%$ of the total GDP, and 5-17\% of total exports (Behnke, 2010).

Cattle play a significant role in the socio-economic aspects of the life of the people of Ethiopia providing products like meat and milk, drought power for cultivation of the agricultural lands of many farmers (Gashaw et al., 2014). Skin and hides are also important products of the livestock sector in generating foreign export earnings (Gashaw et al., 2014). However, the overall contribution of livestock to food production, rural income and export earnings from livestock have been far below than the expected potential due to the combined effects of external parasites like ticks, Tick-Borne Diseases (TBDs)(Peter et al., 2005).

Ticks are blood sucking ecto-parasites which belongs to the phylum Arthropoda categorized under the three families of the Argasidae, the Ixodidae and the Nuttalliellidae (Anderson, 2008). According to Walker et al (2003) and Guglielmone et al (2010), the family Ixodidae contains the important genera of Amblyomma, Dermacentor, Haemaphysalis, Hyalomma, Rhipicephalus and formerly of the genus Boophilus are now classified as a sub genus within the genus Rhipicephalus. Family Argasidae contains Argas, Ornithodoros, and Otobius and a family Nuttalliellidae comprises a single species, Nuttalliella namaqua (Guglielmone et al., 2010).

Heavy infestations of ticks for example of $R h$. decoloratus on the body of the host are likely to cause damage to hides and reduce the rate of growth of cattle (Walker et al., 2003). Bekele (2002) estimates an annual loss of US $\$ 500,000$ from hide and skin down grading due to ticks, and approximately $65.5 \%$ of major defects of hides by ticks in eastern Ethiopia.

Ticks are responsible for severe economic losses both through direct and indirect effect of blood sucking and toxins particularly in cattle in terms of milk production and reduced weight gain (Bekele, 2002; Peter et al., 2005). For example in Ethiopia, TBD together with tsetse and trypanosomosis are economically very important diseases for this sector (Bekele, 2002). They also indi- 
rectly affect their hosts by transmitting a greater variety of pathogenic micro organisms than other arthropod vector groups while feeding their blood meal (Jongejan and Uilenberg, 2004). They affect the physiology of the animals as well (Bekele et al., 2011) and they may also cause nonspecific symptoms like anemia, dermatosis, toxicosis and paralysis (Wasihun and Doda, 2013).

Nowadays, ticks and tick borne diseases represent a major problem to cattle production. They are widely distributed throughout the world, particularly in tropical and subtropical countries (Oluwoch et al., 2009) and have been estimated to affect $80 \%$ of the world cattle (Regasa et al., 2015). Ticks reduce the productivity of indigenous cattle due to their ability to transmit different tick borne diseases like protozoan, Rickettsia and viral diseases (Rajput et al., 2006).

Economically, the most important ixodid ticks of cattle in tropical regions belong to the genera of Hyalomma, subgenus Boophilus, Amblyomma and, Rhipicephalus (Lefebvre et al., 2010). Of the 47 species of ticks reported from Ethiopia, most of them have been implicated as vectors for several diseases (Mekonnen et al., 2001; Kumsa et al., 2015, 2016). Amblyomma variegatum (A.variegatum), A.gemma, A. cohaeruns, and Rhipicephalus (Boophilus) decoloratus are among the most important ixodid ticks (Mekonnen et al.,2001; Kumsa et al., 2016). Rhipicephalus pravus, R. evertsi, $R$. practextatus, $R$. muhasmae, $R$. bergeoni, R. simus have been also reported (Mekonnen et al.,2001; Kumsa et al., 2016). Hyalomma dromedarii, H. trucatum, H. rufipes H. excavatum, H. impelatumwere also previously identified (Walker et al., 2003; Kumsa et al., 2016).

However, in the present study area no research has been carried out previously on the prevalence and identification of ixodid ticks at genera and species level. Therefore, the current study was aimed to estimate the overall prevalence of ixodid ticks on cattle and identify the ticks at genera and species level.

\section{Materials and methods}

\section{Study area}

This cross sectional study was conducted in Semi-arid areas of Raya Azebo district which is located at $12^{\circ} 477^{\prime} 55^{\prime \prime N}$ North and $039^{\circ} 38^{\prime} 45^{\prime \prime}$ East. The district is found at about $128 \mathrm{~km}$ south of Mekelle, the capital city of Tigray region, Ethi-

Ethiop. Vet. J., 2018, 22 (2), 53-64 
opia. It is also about $662 \mathrm{~km}$ north of Addis Ababa, the capital city of Ethiopia. The administrative center of the district is Mehoni. According to Bewket et al (2015), the agro-ecology of the district covers midland (80.6\%), lowland (18\%) and highland (1.4\%). The altitude of the district ranges from 923-2300 meters above sea level.

\section{Study design}

A cross sectional study was conducted from January to December; 2016. Study animals were selected from district veterinary clinics, animal health posts, communal grazing lands as well as small scale farms regardless of the agroclimatic zones of the study area, sampling season and months, herd size, management practices, and animal health status. Simple random sampling was used for both infested and non-infested local cattle breeds in relation to their age, sex and body conditions to collect ticks for the identification at genera and species level and to determine their prevalence.

\section{Sample size determination}

The sample size for this study was determined by assuming the expected prevalence of $50 \%$ tick infestation as there was no previous research conducted in the study area. The desired sample size for the study was calculated using the 95\% confidence interval and at 5\% absolute precision using the formula indicated below (Thrusfield, 2005).

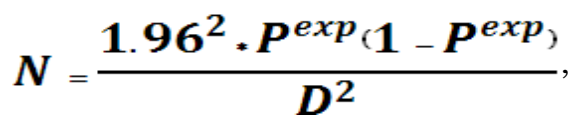

Where

$\mathrm{N}=$ required sample size $\mathrm{P}^{\mathrm{exp}}=$ expected prevalence. $\mathrm{D}=$ desired absolute precision.

Accordingly, the required study sample size was estimated to be 384 . However, to increase precision, the study sample size was increased and total of 448 study animals were examined in the study. 


\section{Sampling and sample processing}

The examined animals were grouped in to three ages as 6 month to 2 years, 2-5 years and greater than 5 years old (Werede and Afera, 2014) and the body condition categories were classified as poor, medium and good (Tola et al., 2016).

\section{Tick sampling procedure and identification}

The selected animals were restrained properly and the entire body of the animals was checked for at least one tick infestation. After physical examination for the presence or absence of ticks, representative sample ticks were collected from different body parts of the animal using a pair of blunt forceps for genera and species identification at Mekelle University, College of Veterinary Medicine, Parasitology Laboratory. The collected ticks were taken carefully and preserved in glass bottles half-filled with $70 \%$ ethanol (Tadesse et al., 2012). Each bottle was tightly plugged with a rubber plug and labeled site of collection, age, sex, animal number/code and date of collection. Identification of the ticks in to different genera and species level was conducted using stereomicroscope based on the standard identification keys given by Walker et al (2003).

\section{Data analysis}

Data analysis was performed using Stata version 10 software. Both descriptive and inferential statistics were performed for the specified objectives. Chisquare test was used to determine the significant variation on tick prevalence among different risk factors like age, sex and body condition of the examined cattle. In all cases, 95\% confidence level with the P-value of less than 0.05 was considered as statistically significance level.

\section{Results}

In this study, the overall prevalence of tick infestation was $90 \%(405 / 448)$. Cattle were found to be positive for at least one tick genera and /or species (Table 1). 
Hadgu et al.,

Table 1. Prevalence of cattle ticks in the examined cattlein Raya Azebo District, Northern Ethiopia

\begin{tabular}{llcccc}
\hline Risk factors & & $\begin{array}{l}\text { No. } \\
\text { Positive } \\
\text { Cattle }\end{array}$ & $\begin{array}{l}\text { Overall } \\
\text { Prevalence }\end{array}$ & $\mathbf{X}^{2}$ & P-value \\
\hline Sex & Female (229) & 208 & $91 \%$ & 0.099 & 0.753 \\
& Male (219) & 197 & $90 \%$ & & 0.342 \\
Age & Total (448) & 405 & $90 \%$ & 2.146 & \\
& 6months -2years(62) & 56 & $90 \%$ & & 0.951 \\
B-5yeras (289) & 260 & $90 \%$ & & \\
condition & Mood (27) & 89 & $92 \%$ & & \\
& Medium (376) & 405 & $90 \%$ & & \\
& Poor (45) & 19 & $70 \%$ & & \\
\hline
\end{tabular}

A total of 2697 ixodid ticks were collected of which R.pulchellus, R. eversi, Rh (B). decoloratus, $A$. variegatum, $A$. gemma and $H$. trun catum tick species that belongs to the genera of Rhipicephalus(54\%), subgenus Boophilus(5\%), Amblyomma(3\%) and Hyalomma(2.7\%) were identified morphologically (Table 2).

Table 2. Identified cattle ticks genera and species in Raya Azebo district, northern Ethiopia

\begin{tabular}{llcc}
\hline $\begin{array}{l}\text { Observed } \\
\text { Genera }\end{array}$ & Observed species & $\begin{array}{l}\text { No of positive } \\
\text { animals }\end{array}$ & $\begin{array}{c}\text { Genera } \\
\text { Prevalence } \\
\text { in \% }\end{array}$ \\
\hline Rhipicephalus & $\begin{array}{l}\text { Rhipicephaluspulchellus } \\
\text { Rhipicephalusevertsi }\end{array}$ & 238 & $242(54.0)$ \\
$\begin{array}{l}\text { Subgenus } \\
\text { Boophilus }\end{array}$ & Boophilusdecoloratus & 4 & $22(5)$ \\
Amblyomma & Amblyommavariegatum & 22 & $13(3)$ \\
Hemblyommagemma & 9 & $12(2.7)$ \\
$\begin{array}{l}\text { Mixed } \\
\text { infestation }\end{array}$ & Hyalommatruncatum & 4 & $116(26)$ \\
Total & & 12 & $405(90)$ \\
\hline
\end{tabular}


Moreover, the prevalence of all tick genera and species was compared for all possible risk factors. The overall prevalence of Rhipicephalus (54\%) and $R$. pulchellus (53\%) were higher as compared to the other tick genera and species (Table 3) respectively. Therefore, Rhipicephalus tick at genera and species level was the dominant tick which inflicted lesions. Regarding related risk factors in the study, there was no variation in the prevalence of genera between sex and animals with different body condition groups.

Table 3. The distribution of tick species among/between the different ages, sexes and body conditions of cattle

\begin{tabular}{|c|c|c|c|c|c|c|c|c|}
\hline \multirow{2}{*}{\multicolumn{2}{|c|}{$\begin{array}{l}\text { Risk factors } \\
\text { Rp }\end{array}$}} & \multicolumn{5}{|c|}{ Species prevalence } & & \multirow[t]{2}{*}{ Total } \\
\hline & & Ree & Bd & Av & $\mathrm{Ag}$ & Ht & & \\
\hline \multirow[t]{4}{*}{ Age } & $\begin{array}{l}\text { 6mnth- } \\
2 \mathrm{yrs}(62)\end{array}$ & $39(63 \%)$ & $2(3 \%)$ & $5(8 \%)$ & $(1 \%)$ & 0 & $0(0)$ & $56(90 \%)$ \\
\hline & $3-5 y r s(289)$ & $142(49 \%)$ & 0 & $14(5 \%)$ & $5(2 \%)$ & $4(1 \%)$ & $10(3 \%)$ & $260(90 \%)$ \\
\hline & $>5 \operatorname{yrs}(97)$ & $57(59 \%)$ & $2(2 \%)$ & $3(3 \%)$ & $2(2 \%)$ & 0 & $2(2 \%)$ & $89(92 \%)$ \\
\hline & Total (448) & $238(53 \%)$ & $4(1 \%)$ & $22(5 \%)$ & $9(2 \%)$ & $4(1 \%)$ & $12(3 \%)$ & 405 \\
\hline \multirow[t]{3}{*}{ Sex } & Male (219) & $116(53 \%)$ & $1(0.5 \%)$ & $13(6 \%)$ & $4(1 \%)$ & $1(0.5 \%)$ & $5(2 \%)$ & 197(90\%) \\
\hline & Female(229) & $122(53.3 \%)$ & $3(1 \%)$ & $9(4 \%)$ & $5(2 \%)$ & $3(1 \%)$ & $7(3 \%)$ & $208(91 \%)$ \\
\hline & Total (448) & $238(53 \%)$ & $4(1 \%)$ & $22(5 \%)$ & $9(2 \%)$ & $4(1 \%)$ & $12(3 \%)$ & 405 \\
\hline \multirow{4}{*}{$\begin{array}{l}\text { Body } \\
\text { condition }\end{array}$} & Good (27) & $14(52 \%)$ & 0 & 0 & $2(7 \%)$ & 0 & 0 & $20(74 \%)$ \\
\hline & $\begin{array}{l}\text { Medium } \\
(376)\end{array}$ & 198(53\%) & $4(1 \%)$ & $20(6 \%)$ & $5(1 \%)$ & $4(1 \%)$ & $10(3 \%)$ & $340(90 \%)$ \\
\hline & Poor (45) & $26(58 \%)$ & 0 & $2(2 \%)$ & $2(2 \%)$ & 0 & $2(4 \%)$ & $45(100 \%)$ \\
\hline & Total (448) & $238(53 \%)$ & $4(1 \%)$ & $22(5 \%)$ & $9(2 \%)$ & $4(1 \%)$ & $12(3 \%)$ & 405 \\
\hline
\end{tabular}

variegatum, Ag-Amblyomma gemma, Ht-Hyalomma truncatum

\section{Discussion}

The overall prevalence of tick in this study was higher than previous studies in different parts of Ethiopia: 74\% in and around Bahrdar (Gedilu et al., 2014); 86.1\% in Werieleke district (Werede and Afera, 2014), $84.1 \%$ in and around Haramaya town (Bedasso et al., 2014) and 56.2\% in Dangila district (Admassu et al., 2015). The highest prevalence in this study may be due to less awareness of the livestock herders, less attention given for cattle management and climatic suitability of the study area for tick development such as high temperature and erratic precipitation. Moreover, the researchers believe that 
the recent drought (2015) could have played a role in reducing the immunity of animals and increasing their susceptibility to the tick infestation through creating suitable condition for tick development. On the other hand, the present study is not in line with the finding reported by Guglielmone et al (2010) with a prevalence of $25.64 \%$. The differences among these results could be due to the agro-ecology, animal health practice, or management difference with in their respective study areas.

In the study, no statistically significant $(p>0.05)$ association was observed between prevalence of ticks and risk factors due to agro-ecological settings and animal health practices and this is in agreement with previous findings reported by Bedasso et al (2014); Kassa and Yalew (2012); Haile and Zeryehun(2013); Wolde and Mohamed (2014). All animals in the present study area were managed almost in the same manner. However, male animals were less infested than female animals probably due to male animals receive a little bit better management compared to females for different purposes.

However, Gedilu et al (2014) reported a statistically significant difference in prevalence among the age groups. Moreover, Gashaw et al (2014) reported a relatively higher prevalence of ticks in adult cattle than younger. Similar result but statistically not significant was found in the present study may be due to age advancement of the animals which may let them to be less resistant. Regarding the different body condition scores, there was no statistically significant variation in the prevalence of ticks due to the high prevalence of ticks in the area. However, a higher proportion of tick prevalence (100\%) was recorded in poor body conditioned animals compared to animals with good and medium body conditioned. This could be due to the fact that poor body conditioned animals have reduced their body energy resistance and lack of enough body potential to build resistance than medium and good body conditioned animals which were less infested and this was in agreement with the previous finding reported by Gedilu et al (2014), in and around Bahridar.

Regarding the tick species which belong to the Generas of Rhipicephalus (54\%), subgenus Boophilus (5\%), Amblyomma(3\%) and Hyalomma (2.7\%) found in this study were similar with the previous reports from different parts of Ethiopia (Admassu et al., 2015; Bedasso et al., 2014; Kiros et al., 2014; Mekonnen et al., 2001; Werede and Afera, 2014). In the present study, R. pulchellus was highly abundant tick species and this is due to the fact that this tick is identified as a tick of tropical and sub-tropical regions (Walker et al., 2003). Rhipi- 
cephalus(54\%) and R. pulchellus, 53\% in all age groups was higher as compared to the other tick genera and species. However this result does not agree with that of Werede and Afera (2014) who reported Amblyomma (75.6\%) and Rhipicephalus (8.8\%).

During the study period, the prevalence of the Rhipicephalus, $55 \%$, and $R$. pulchelus, 53.3\% identified at genera and species level respectively was slightly higher in female as compared to male but there was no statistically significant $(p>0.05)$ association with the sex of the examined cattle because this type of ticks do not have special selection for one sex over the other feeding behavior. This result was in line with the works done by Wolde and Mohamed (2014) in Sodozuria district and Gedilu et al (2014) in and around Bahirdar who reported the prevalence of this genera and species were higher in female (2.5\%) but disagreed with the report given by Werede and Afera (2014) who recorded the overall prevalence Rhipicephalus is higher in male (5.3\%).

\section{Conclusion}

Tick prevalence in Raya Azebo district is high and its impact on cattle health and prevalence of tick-borne diseases needs to be analyzed and adequate control measures implemented. Therefore, a detailed analysis of the relationship between tick abundance and environmental variables needs to be carried out to improve tick control. Community should be well informed about the impact of these ecto-parasites and proper prevention and control options. Further studies need to be conducted for investigation of impact of climate change and variability's, soil moisture, vegetation coverage on tick borne diseases development and cattle population dynamics.

\section{Conflict of interest}

The authors declare that there is no conflict of interest.

\section{Acknowledgements}

The authors would like to thank the owners of the examined local cattle breeds for their cooperation during sample collection and the district staff members of the office of agriculture and veterinary clinic experts for their endless support.

Ethiop. Vet. J., 2018, 22 (2), 53-64 
The authors acknowledge Regional Universities Forum(RUFORUM) under the project for crop-livestock value chain for financial support and Institute of Climate and Society of Mekelle University for the technical support.

\section{References}

Admassu, B., Yeneneh, H., Shite, A., Haile, B. and Mohammed, S., 2015. Prevalence and Identification of Major Ixodid Tick Genera of Cattle in Dangila District, Awi Zone, North West Ethiopia. Acta Parasitol. Globalis.,6(2), 129-135.

Anderson, J.F. and Magnarelli, LA., 2008. Biology of ticks. Infect. Dis. clin. N. Amer., $22,195-215$.

Bedasso, M., Abebe, B. and Degefu, H.,. 2014. Species composition, prevalence and seasonal variations of ixodid cattle ticks in and around Haramaya town, Ethiopia. J. Vet. Med. Anim. Hlth., 6, 131-137.

Behnke, R.H., 2010. The Contribution of Livestock to the Economies of IGAD Member States: Study Findings, Application of the Methodology in Ethiopia and Recommendations for Further Work.IGAD LPI Working Paper No. 02 - 10. Study Findings, Application of the Methodology in Ethiopia and Recommendations for Further Work. IGAD Livestock Policy Initiative.

Bekele, J., Tariku, M. and Abebe, R., 2011. External Parasite Infestations in Small Ruminants in Wolmera District of Oromiya Region, Central Ethiopia. J. Anim. Vet. $A d v ., 10,518-523$.

Bekele, T., 2002. Studies on seasonal dynamics of ticks of Ogaden cattle and individual variation in resistance to ticks in eastern Ethiopia. J. Vet. Med., 49, 285-288.

Bewket, W., Radeny, M. and Mungai, C., 2015. Agricultural Adaptation and Institutional Responses to Climate Change Vulnerability in Ethiopia.CCAFS Working Paper no. 106. Copenhagen, Denmark: CGIAR Research Program on Climate Change, Agriculture and Food Security (CCAFS).

Gashaw, T., Asresie, A. and Haylom, M., 2014. Climate change and livestock production in Ethiopia. Acad. J. Env. Sci., 2(4), 059-062

Gedilu, M., Mohammed, A., and Kechero, Y., 2014. Determination of the prevalence of ixodid ticks of cattle breeds, their predilection sites of variation and tick burden between different risk factors in Bahir Dar, Ethiopia. Global Vet.,13 (4), 520-529.

Guglielmone, A.A., Robbins, R.G., Apanaskevich, D.A., Petney, T.N., Estrada-Peña, A., Shao, R. and Barker, S.C., 2010. The Argasidae, Ixodidae and Nuttalliellidae (Acari: Ixodida) of the world: a list of valid species names. Zootaxa., 2528, 1-28. 
Haile, S.O. and Zeryehun, T.Z., 2013. Prevalence of ectoparasite infestations of cattle in Bench Maji zone, southwest Ethiopia. Vet.World., 6, 291-294.

Jongejan, F. and Uilenberg, G., 2004. The global importance of ticks. Parasitol., 129(S1), S3-S14.

Kassa, S.A. and Yalew, A., 2012. Identification of ixodid ticks of cattle in and around Hararamaya district, Eastern Ethiopia. Sci. J. Crop Sci.,1, 32-38.

Kiros, S., Awol, N., Tsegaye, Y. and Hadush, B., 2014. Hard Ticks of Camel in Southern Zone of Tigray, Northern Ethiopia. J. Parasitol. Vector Biol., 6, 151-155.

Kumsa, B., Socolovschi, C., Raoult, D. and Parola., P., 2015. Spotted fever group Rickettsiae in ixodid ticks in Oromia, Ethiopia. Ticks and Tick-borne Dis., 6 (1), 8-15.

Kumsa, B., Laroche, M., Almeras, L., Mediannikov, O., Raoult, D. and Parola.P., 2016. Morphological, molecular and MALDI-TOF mass spectrometry identification of ixodid tick species collected in Oromia, Ethiopia. Parasitol. Res., 115 (11), 4199 4210.

Lefebvre, P.C., Blancou, J.,Chermette, R. and Uilenberg,G., 2010. Infectious and Parasitic diseases of livestock. Volume 1,R Chermette, Alfort National Veterinary School, France, GUilenberg, Pp, 93-128.

Mekonnen, S., Hussein, I. and Bedane, B., 2001. The distribution of ixodid ticks (Acari: Ixodidae) in central Ethiopia. Onderstepoort J.Vet. Res., 68, 243.

Oluwoch, J.M, Revers, B. and van Jaarsveld, A. S., 2009. Host parasite distribution pattern under stimulated climate implications for tick-borne diseases. Int. J. Climatol., 29, 993-1000.

Peter, R.J., Van den Bossche, P.,Penzhorn and B. L., Sharp, B., 2005. Tick, fly, and mosquito control lessons from the past, solutions for the future. Vet. Parasitol., 132, 205-215.

Rajput, Z.I., Hu, S.H.,Chen, W.J. and Xiao, C.W., 2006. Importance of ticks and their chemical and immunological control in livestock. J. Zhejang University Sci., 7, 912-921.

Regasa, D.T., Tsegaye, K.A., and Waktola, H., 2015. Prevalence of major ectoparasites of calves and associated risk factors in and around Bishoftu town. Afr. J. Agric. Res., 10 (10), 1127-1135.

Tadesse, F., Abadfaji,G.,Girma,S., Kumsa,B., Jibat,T. and 2012. Identification of tick species and their preferred site on cattle's body in and around Mizan Teferi, Southwestern Ethiopia. J. Vet. Med. Anim. Hlth., 4 (1), 1-5.

Thrusfield, M., 2005.Veterinary Epidemiology, $3^{\text {rd }}$ ed. Black well publishing, Garsington road, Oxford, UK. Pp. 233-250.

Ethiop. Vet. J., 2018, 22 (2), 53-64 
Tola, M., Kebede, B., Kitila, G. and Gezehegn, E., 2016. Prevalence of bovine trypanosomosis and its vector apparent density in Chora District of Illuababora Western Oromia, Ethiopia. J. Vet. Med. Anim. Hlth., 8 (7), 64-71.

Walker, A.A., Bouatour, J.L., Camicas,A.A., Estadapena, I.G., Harok, A.A, Hatif, R.G., Pegram and P.M. Preton., 2003. Ticks of domestic animals in Africa: A guide to identification species.The University of Edinburgh. UK, Pp. 67-80.

Wasihun, P., and Doda, D., 2013. Study on prevalence and identification of ticks in Humbo district, Southern Nations, Nationalities, and Peoples Region (SNNPR), Ethiopia. J. Vet. Med. Anim. Hlth., 5 (3), 73-80.

Werede, H., and Afera,B., 2014. Prevalence of Ixodid Ticks on Bovine of Werieleke Wereda, Tigray. Acta Parasitol. Globalis., 5 (2), 146-150.

Wolde, A., and Mohamed, A., 2014. Prevalence of Ixodid Ticks on Bovine in Soddo Zuria Districts, Wolaita Zone, Ethiopia. Acta Parasitol. Globalis., 5 (3), 188-197. 